\title{
DESARROLLO TURÍSTICO, PROMOCIÓN INMOBILIARIA Y DEGRADACIÓN MEDIOAMBIENTAL EN EL MUNICIPIO DE BENITACHELL (COMARCA DE LA MARINA)
}

\author{
Cristina Montiel Molina
}

\begin{abstract}
RESUMEN
La especialización turístico-residencial de la franja litoral alicantina se manifiesta en una sustancial transformación de su estructura territorial y urbanística, como consecuencia de los cambios experimentados por el modelo socio-económico dominante. En este contexto, el municipio de Benitachell, por distintos motivos, recibe el impacto de forma tardía y singular; a los notables beneficios económicos derivados de la implantación del turismo se contrapone la degradación medioambiental inherente a la nueva actividad.

\section{RÉSUMÉ}

La spécialisation touristique-résidentielle du littoral d'Alicante a provoqué une nette transformation de la structure territoriale et urbanistique, à cause des changements du système socio-économique. Dans ce contexte, le «municipio» de Benitachell, pour diverses raisons, reçoit l'impact tardivement et d' une façon singulière. La dégradation de l'environnement, inhérente à la nouvelle activité, s'oppose aux avantages économiques dérivées de l'implantation du tourisme.
\end{abstract}

El municipio de Benitachell pertenece a la comarca alicantina de La Marina, y se encuentra situado al norte de la provincia. La superficie de su término es de $12,5 \mathrm{Km}^{2}$, encontrándose su punto culminante marcado por el vértice geodésico del Puig Llorença, próximo éste a la línea de costa. Pese al carácter accidentado de la topografía del municipio, cabe establecer una diferenciación entre la zona interior, caracterizada por una topografía más regular y con una vocación preferentemente agraria, donde tradicionalmente se ha concentrado un mayor volumen de población; y la sierra litoral, marco de implantación a partir de la década de los setenta de un complejo turístico-residencial que ha reportado cuantiosos beneficios económicos al municipio a costa de un notorio e irreparable deterioro paisajístico.

El modelo de implantación y desarrollo de la actividad turística en Benitachell singu- 
lariza al municipio en el contexto de la dinámica del turismo alicantino. A pesar de su condición de municipio costero, Benitachell entró de forma tardía en el proceso de ordenación de espacios turísticos litorales, debido a una serie de condicionamientos físicos y humanos que justifican la perduración de las tradiciones agrarias en el municipio.

Las causas fundamentales del retraso con que la nueva especialización económico-territorial llegó a Benitachell fueron el retranqueamiento del núcleo urbano respecto a la línea de costa y el aislamiento respecto de la misma debido a la presencia de la sierra litoral del Puig de Llorença ${ }^{1}$. Por otra parte, la carencia de playas y el predominio de una costa alta y accidentada restó atractivo al municipio durante la década de los años sesenta. El turismo masivo de aquel momento buscaba las playas de arena y en Benitachell no encontraba sino algunas calas, resultado de la colmatación aluvial de los barrancos, tales como la Cala de los Tiestos en la desembocadura del Barranco Falqui, la Cala asociada al Barranco de la Viuda y la Cala de la Granadella.

Además del condicionante topográfico, la implantación de una infraestructura turística tropezó desde el primer momento con el obstáculo planteado por la problemática del agua, común a toda la comarca del Marquesado. Tradicionalmente, Benitachell se había venido abasteciendo del agua de lluvia almacenada en los aljibes, así como de la obtenida a partir de los pozos realizados en el acuífero de Benisa. Sin embargo, la construcción del complejo residencial del Puig y la implantación del fenómeno turístico en el municipio desencadenaron un notorio incremento de la demanda y generaron conflictos de aprovechamiento con otros usuarios. Conviene señalar, no obstante, que la agricultura no se vio perjudicada por la competencia en el uso del agua, ya que fundamentalmente se trata de una agricultura de secano que plantea exigencias hídricas mínimas. El problema que realmente preocupaba al municipio era el cuestionamiento del desarrollo turístico ante la escasez de dotación de agua. A esta preocupación responde la adquisición realizada en 1972 por el Ayuntamiento de un pozo en la partida de Lluca, cuyo aforo era de 540 litros/minuto. Dicha dotación resultaba de todos modos insuficiente para asegurar el abastecimiento de la futura urbanización «Cumbre del Sol», por lo que se recurrió al suministro a partir de los pozos situados en Orba, al tiempo que se fomentaba la realización de diversos estudios encaminados a determinar las zonas más idóneas para ubicar un nuevo pozo en el municipio con que reforzar los caudales ya existentes. Los estudios fueron llevados a cabo por D. José Fuster Cantalles y por D. Marcelo Burgos Teruel en 1986, señalando este último como mejor emplazamiento para realizar el sondeo la zona del Tosal, en la partida del Abiar, junto al término de Teulada. Esta hipótesis fue comprobada y materializada en febrero de 1988, al ser alumbrado en aquella zona un nuevo pozo con capacidad aproximada de unos 400 litros/minuto, lo que venía a asegurar el relanzamiento del turismo y el desarrollo de la industria de la construcción y del sector terciario en el municipio.

En efecto, el auge de ciertas ramas industriales conectadas al proceso de ordenación de espacios turísticos y de las actividades propias del sector terciario ha sido una de las mayores repercusiones territoriales del desarrollo turístico en el municipio. Benitachell ha sido tradicionalmente un municipio agrícola y pesquero, sin embargo, a partir de la segunda mitad de la década de los años setenta, estas actividades económicas tradicionales han sido desplazadas por el auge de los sectores secundario y terciario. En la actualidad, Benitachell responde a la definición de municipio turístico formulada por Vera Rebollo, en tanto en cuanto ha contado con un planeamiento tendente a potenciar la

\footnotetext{
${ }^{1}$ COSTA MAS, J. El Marquesat de Denia, Departamento de Geografía de la Universidad de Valencia, 1977, p. 534.
} 
actividad turística en detrimento de las actividades tradicionales, que han quedado relegadas a posiciones marginales ${ }^{2}$. Este hecho queda evidenciado por la clasificación del suelo definida en las Normas Subsidiarias del municipio, donde el suelo apto para urbanizar, junto con el suelo ya ordenado por planes parciales aprobados, alcanzan una considerable extensión superficial. En efecto, la cifra de 777 hectáreas de suelo calificado por el planeamiento por las Normas Subsidiarias contrasta fuertemente con el total de 40 hectáreas calificadas en el antiguo Plan General de Ordenación Urbana de Benitachell, si bien es preciso añadir a esta cifra el volumen de suelo clasificado como Rústico de Interés Turístico por el Plan General de Ordenación Urbana de 1973 y sobre el que se han promovido los Planes Parciales de «Pueblo Alcasar», «El Madroñal», «Golden Valley» $\mathrm{y}$ «Valle del Portet» ${ }^{3}$. En la actualidad han sido ya ordenadas por sucesivos Planes Parciales 455 hectáreas de las 777 hectáreas calificadas por el planeamiento en 1985.

Otro de los aspectos que ha debido afrontar y superar el municipio con el fin de garantizar el asentamiento de la actividad turística ha sido la existencia de una deficiente red de comunicaciones. El núcleo urbano del municipio se ubica en el interior del término, separado de la costa por el Puig Llorença y construido sobre una loma. Se trata de un pequeño núcleo de estructura medieval, cuyos ensanches han sido trazados sobre la vertiente meridional de la loma, de modo que el originario plano lineal del pueblo ha ido ramificándose con sucesivas ampliaciones hasta dar lugar en la actualidad a una configuración ecléctica y tentacular. Los ensanches se apoyan en vías de comunicación interurbana que han generado una tipología edificatoria abierta. En este contexto, la red de carreteras es el único medio de comunicación terrestre con que cuenta Benitachell, que, de hecho, se encuentra ubicado en una encrucijada de caminos: Jávea por dos direcciones, Teulada, Moraira y la urbanización «Cumbre del Sol». Por ello, entre los objetivos urbanísticos y la estrategia de ocupación del territorio propuestos en las Normas Subsidiarias de Planeamiento, destaca la intención de mejorar el actual sistema de carreteras y, del mismo modo, cada uno de los Planes Parciales aprobados prevé la ejecución de las obras de infraestructura viaria oportunas para permitir el fácil acceso a las urbanizaciones planificadas.

\section{Modelo turístico y agentes sociales}

Benitachell debe ser interpretado como municipio litoral de segunda línea, que ofrece al turismo los atractivos de la tranquilidad, la proximidad al mar, la calidad paisajística y, sobre todo, los rasgos propios del clima mediterráneo, caracterizado por la benignidad del régimen térmico, la escasez de precipitaciones y el predominio de cielos despejados, con elevadas fracciones de insolación; en consecuencia, el modelo de turismo implantado ha sido el de carácter residencial. De manera paralela, se ha desarrollado un proceso de remodelación de la vivienda rural tradicional, con la finalidad de transformarla en vivienda de ocio.

El turismo de tipo residencial, basado en la construcción de urbanizaciones planificadas, responde fundamentalmente a la demanda de una clientela extranjera que busca parajes retirados de los grandes núcleos masificados y que en su mayoría está compuesta

${ }^{2}$ VERA REBOLLO, J. F. «Turismo y Territorio», XI Congreso Nacional de Geografía, 1989, p. 17.

${ }^{3}$ PEÑIN, A. «La Marina. Metrópoli rural o campo urbanizado», Urbanismo en áreas turísticas, Revista del Colegio Oficial de Arquitectos de Madrid, n. ${ }^{\circ}$ 4, mayo 1988, pp. 47-54. 
por pensionistas que residen en la urbanización durante casi todo el año. Se trata de un turismo selectivo, integrado por residentes extranjeros permanentes o semipermanentes $\mathrm{y}$, en menor medida, por residentes vacacionales. En efecto, en la urbanización «Cumbre del Sol» la mayoría de los propietarios son de origen alemán, suizo y británico, mientras que en «Pueblo Alcasar» la nacionalidad que cuenta con una mayor representación es la belga, ocupando el grupo de los españoles el segundo puesto.

La configuración de estos núcleos de residentes extranjeros se ha basado en la promoción en el extranjero por medio de agentes de ventas. De hecho, buena parte de las operaciones se han realizado a través de catálogo y de folletos que exhiben «slogans» propagandísticos tales como el apelativo que se atribuye a la «Cumbre del Sol» en uno de los paneles dispuestos en la carretera de acceso a la urbanización: «Paradise of the Costa Blanca».

Uno de los indicadores más útiles y significativos para estudiar la evolución que ha seguido el modelo de implantación turística en Benitachell es la evolución de la población de origen extranjera que habita en el municipio. El análisis de los Padrones Municipales de Habitantes de Benitachell de 1975, 1981 y 1986 nos ha permitido deducir que esta evolución ha sido muy rápida y que se encuentra en relación de dependencia directa respecto al desarrollo de las urbanizaciones turístico-residenciales. En efecto, el Padrón de 1975 nos ha permitido confirmar que en esta fecha sólo habitaban diez personas de origen extranjero en el municipio y que además se trataba de hijos de emigrantes españoles cuyos padres eran vecinos de Benitachell, o bien de inmigrantes de origen «pied noir». Es en 1977 cuando llegaron al municipio las dos primeras familias de origen extranjero y se ubicaron con carácter de residentes permanentes en las partidas dels Molins y de Benitachells. Según el Padrón de 1981, eran 45 los habitantes de origen extranjero con residencia permanente en Benitachell, y se encontraban todos ellos concentrados en las urbanizaciones de la «Cumbre del Sol» $\mathrm{y}$ «Pueblo Alcasar», siendo el grupo belga el más numeroso. Por último, y según los datos más recientes de que disponemos, eran 149 los residentes procedentes del extranjero que habitaban en Benitachell según el Padrón de 1986, y respondían a las nacionalidades que indicamos a continuación:

\begin{tabular}{|c|c|c|}
\hline 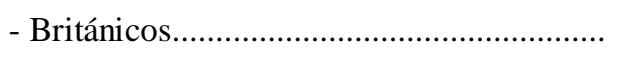 & 57 & (29 jubilados) \\
\hline - Belgas... & 24 & (14 jubilados) \\
\hline - Alemanes....... & 19 & (7 jubilados) \\
\hline 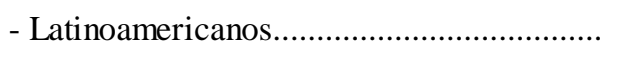 & 14 & \\
\hline - Holandeses.............. & 12 & (5 jubilados) \\
\hline - Franceses.......... & 11 & \\
\hline - Suizos... & 5 & (3 jubilados) \\
\hline - Daneses............ & 3 & (2 jubilados) \\
\hline - Luxemburgueses..... & 2 & \\
\hline - Africanos......................... & 2 & \\
\hline 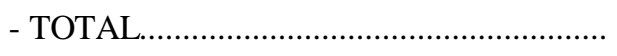 & 149 & (60 jubilados) \\
\hline
\end{tabular}

La relación expuesta pone de manifiesto la trascendencia de los efectos que desencadena el fenómeno turístico en la estructura demográfica del municipio, así como la importancia que adquiere el grupo formado por extranjeros pensionistas en las urbanizaciones turístico-residenciales.

Aunque con efectos territoriales de menor entidad, destaca también el fenómeno de rururbanización o rehabilitación funcional del hábitat rural que se ha desarrollado de 
modo paralelo a la construcción de urbanizaciones residenciales. Conviene señalar, no obstante, que la definición de rururbanización, entendida como «edificación en el medio rural, sin planeamiento y con un carácter de hábitat diseminado» ${ }^{4}$, no corresponde exactamente al proceso urbanístico que se ha desarrollado en el medio rural de Benitachell, donde lo que en realidad se ha producido es la rehabilitación funcional del hábitat rural tradicional, consistente en la ejecución de obras menores. Se trata pues de viviendas rurales que han sido reconvertidas funcionalmente, de modo que el tradicional riu-rau ha quedado convertido en porche para usos de ocio, al tiempo que los corrales han sido sustituidos por garajes y el suelo enlosado.

La importancia territorial adquirida por el hábitat en diseminado y el desarrollo del citado proceso de rehabilitación funcional de la vivienda tradicional ha llevado incluso a algún autor a hablar de «campo urbanizado» ${ }^{5}$. En realidad, este fenómeno es consecuencia de una estructura minifundista de la propiedad agraria, así como del gran número y reducida extensión superficial de las explotaciones. El hábitat disperso, constituido por casas de campo tradicionales, ha sido transformado en un conjunto de viviendas secundarias como resultado del aumento del nivel de renta alcanzado por la población, de la renovación de las formas de vida, de la evolución de las mentalidades, y de los cambios demográficos de signo positivo. En efecto, la mejora de la calidad de vida en Benitachell, como consecuencia del desarrollo de actividades secundarias y terciarias inducidas por el turismo, ha provocado el retorno de antiguos emigrantes, así como la llegada de nuevos inmigrantes procedentes de otras provincias, atraídos por una vasta y diversificada oferta de empleo. En la actualidad el saldo migratorio del municipio es positivo, ya que Benitachell recibe la inmigración de una mano de obra destinada a las actividades generadas por la proliferación de urbanizaciones. En este sentido, resulta significativo el análisis de la evolución demográfica del municipio desde 1960, que muestra una disminución progresiva de los efectivos demográficos hasta 1975 y una inflexión de la curva de población a partir de esta fecha como resultado de la llegada de inmigrantes. Esta se produce de forma masiva en la década de los ochenta y está integrada por población extranjera, en su mayoría jubilados, y por mano de obra procedente de otras Comunidades Autónomas y empleada fundamentalmente en la industria de la construcción y en el sector terciario.

En consecuencia, tanto el proceso de rururbanización como los cambios demográficos que se han producido en el municipio a partir de la segunda mitad de la década de los años setenta, son el resultado de la configuración de un espacio turístico. La planificación del mismo se ha basado en la actuación de agentes sociales foráneos, que han llevado a cabo la planificación y la construcción de los distintos conjuntos residenciales. Generalmente se trata de sociedades con domicilio social en la comarca, aunque fuera del término de Benitachell. De hecho, las sociedades promotoras domiciliadas en Benitachell se han ido disolviendo paulatinamente, de modo que en la actualidad existe únicamente la sociedad limitada creada en abril de 1987 bajo la denominación de «Constructora de Benitachell, S. L.», cuyo objeto es la construcción de viviendas unifamiliares de segunda residencia en diseminado.

Las operaciones urbanísticas planificadas suelen ser realizadas por una sola persona jurídica, que actúa al tiempo como propietaria, promotora y constructora del Plan Parcial. Así ocurre en la «Cumbre del Sol», cuyos terrenos pertenecen a la empresa promo-

${ }^{4}$ VERA REBOLLO, F. Turismo y urbanización en el litoral alicantino. Alicante, Instituto de Estudios «Juan GilAlbert», 1987, p. 405.

${ }^{5}$ PEÑIN, A. Op. cit., 1988. 
tora «V.A.P.F., S. A.» (Benisa), en el «Valle del Portet» cuyos propietarios promotores son «Valle del Portet, S. A.» (Teulada) y «Casitas Moraira, S. A.» (Moraira); en las urbanizaciones «El Madroñal»y «Golden Valley», pertenecientes a «Promociones Moraira, S. A.» (Moraira), y en la urbanización recientemente planificada de «Les Fonts», propiedad en su mayor parte de la empresa promotora «Osa Mayor, S. L.». Destacan como únicas excepciones a dicha regla las urbanizaciones «Luz y Sol. Pueblo Alcasar» $\mathrm{y}$ «Calistros y Asegaor». En la primera fue promotor el propio Ayuntamiento de Benitachell sobre la propiedad de la empresa «Constructora del Este, S. A.», que desarrolló el Plan Parcial; y en el caso de «Les Fonts» la empresa promotora «Toscamar, S. A.» poseía únicamente el 52,5\% de la totalidad de los terrenos afectados por el Plan Parcial, encontrándose el resto de la superficie repartida entre dieciséis propietarios, vecinos de Benitachell, que se opusieron a la aprobación definitiva del Plan Parcial y al establecimiento de una Junta de Compensación para la gestión del suelo ocupado, tal y como preveía la entidad promotora en el plan redactado. Sin embargo, la práctica totalidad de los terrenos pertenecientes a los alegantes contra el Plan Parcial fueron adquiridos por la empresa «URBECO, S. A.» de Benisa, hasta lograr alcanzar, junto con la propiedad de la entidad promotora, el $90 \%$ de la superficie total planificada. En consecuencia, desaparecieron las causas que motivaron la denegación de la aprobación definitiva del Plan Parcial «Calistro y Asegaor» en octubre de 1988, y éste fue finalmente ratificado por la Comisión Territorial de Urbanismo de Alicante en julio de 1989.

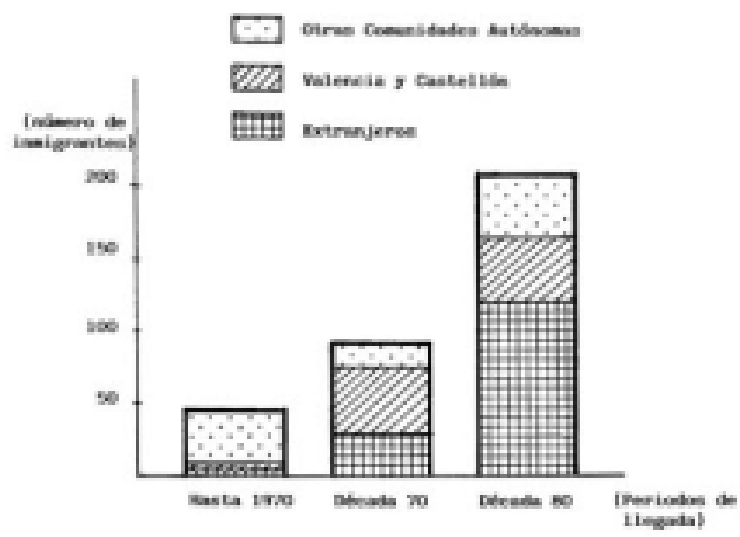

FUENTE: Padrón Municipal de Habitantes de Benitachell 1986. Elaboración propia.

Gráfico 1. Evolución de la recepción de inmigrantes en Benitachell según su origen y fecha de llegada. 


\section{Del Plan Comarcal de la Costa Blanca a las Normas Subsidiarias Municipales de Planeamiento}

El Plan Comarcal de Ordenación de la Costa Blanca, aprobado en junio de 1973 para la zona nororiental de la provincia de Alicante, comprendida entre los municipios de Denia y Villajoyosa, fue concebido como esquema director básico de los planteamientos expuestos en las figuras de planeamiento municipal. Se trataba, por tanto, de un documento de ordenación con carácter supramunicipal, que poseía un rango equivalente al de un Plan Director Territorial de Coordinación. De acuerdo con las directrices contempladas en dicho Plan Comarcal, el planeamiento del municipio de Benitachell se hallaba regulado por un Plan General de Ordenación Urbana que, aprobado el mismo año, no pudo ser desarrollado en todas sus determinaciones, debido a la aprobación el 9 de abril de 1976 de la Ley 19/1975 de 2 de mayo de Reforma de la Ley sobre Régimen de Suelo y Ordenación Urbana.

Con objeto de adaptar el planeamiento municipal a las prescripciones que la nueva Ley de Suelo establecía, el Ayuntamiento de Benitachell preparó la redacción de un nuevo Plan General de Ordenación Urbana, cuya propuesta de aprobación fue desestimada por la Comisión Provincial de Urbanismo en 1978 y 1979, alegando la existencia de reparos y defectos subsanables. Finalmente, el Plan General de Ordenación Urbana fue aprobado por la Comisión Provincial en 1980, a excepción del suelo urbanizable programado, aunque al año siguiente el propio ente jurídico acordó suspender su aprobación, aduciendo que no se habían cumplido las condiciones impuestas en el primer acto aprobatorio. El acuerdo de la Comisión Provincial de Urbanismo quedó ratificado al no ser recurrido por el Ayuntamiento, con lo cual se generó una situación de confusión jurídica: presumiblemente el Plan General de Ordenación Urbana revisado y adaptado era aplicable en sus determinaciones en cuanto al Suelo Urbano, mientras que en lo relativo al Suelo Urbanizable (programado y no programado) se producía un vacío de normativa.

En 1984, tras la realización de una serie de gestiones encaminadas a definir la normativa urbanística municipal, se llegó a la conclusión de que el Plan General de Ordenación Urbana de 1980 sólo constituía una apariencia de legalidad, y que en realidad continuaba vigente el Plan General de Ordenación Urbana de 1973. Ante la situación generada, la Administración Urbanística consideró que convenía realizar la adaptación a la nueva Ley del Suelo mediante la figura de las Normas Subsidiarias de Planeamiento Municipal, con el fin de dar un tratamiento adecuado a las necesidades existentes, buscando un equilibrio entre el suelo apto para urbanizar y el que se pretendía preservar de la obra urbanizadora.

La clasificación del suelo municipal establecida en las Normas Subsidiarias de Planeamiento de Benitachell aprobadas en 1987 dio como resultado la creación de una amplia zona de suelo apto para urbanizar (S.A.U.), dividida en tres subapartados: suelo residencial de ensanche, ciudad-jardín y suelo turístico-residencial. Esta última categoría de suelo, susceptible de ser ordenada para la expansión del turismo, y en la que no se englobaba el suelo ya programado por los Planes Parciales aprobados de modo previo a la redacción de las Normas Subsidiarias de Planeamiento, ocupaba una superficie de 136,70 hectáreas, lo que suponía el 95\% del suelo urbanizable. De todos modos, entre los Planes Parciales anteriores a la aprobación de las Normas Subsidiarias figuraba la urbanización «Cumbre del Sol», cuya extensión superficial $(367,61$ hectáreas) era ya superior a la clasificada como suelo apto para urbanizar. En efecto, el Plan Parcial «Cumbre del Sol», redactado en noviembre de 1973 y aprobado en 1975 constituye la 


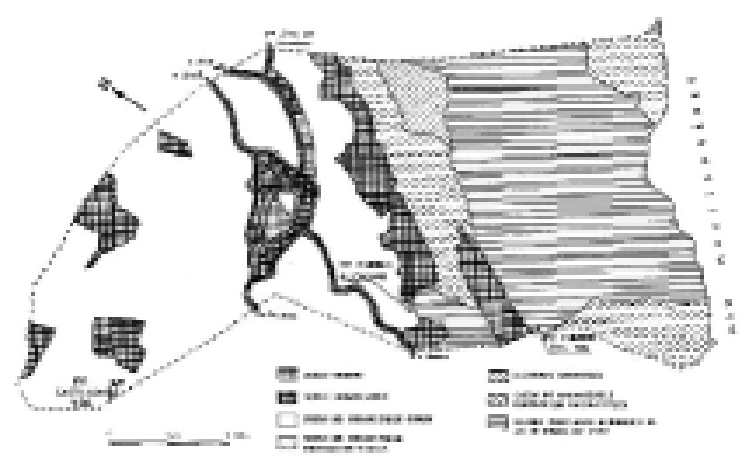

Figura 1. Clasificación del suelo según las Normas Subsidiarias Municipales de Benitachell, aprobadas el 29 de enero de 1987 por la Comisión Provincial de Urbanismo de Alicante. 
mayor actuación urbanística desarrollada en el municipio de Benitachell, y es al mismo tiempo la responsable de la alteración paisajística de la unidad de relieve más importante del término: el Puig Llorença. Los otros tres Planes Parciales que precedieron a las

Normas Subsidiarias de Planeamiento fueron los de «Pueblo Alcasar» (11,60 hectáreas), «El Madroñal» (10,44 hectáreas) y «Castellons Vida» (1,02 hectáreas).

\section{El conflicto «Cumbre del Sol»}

El complejo turístico-residencial «Cumbre del Sol» ha sido implantado sobre un monte que, en sus orígenes, perteneció al común de vecinos del municipio por cesión del Duque de Medinacelli en la Carta Puebla que fue otorgada con motivo de la expulsión de los moriscos. Este monte, que contaba con un aprovechamiento de leñas bajas y de pastos coexistiendo con algún enclave privado de dedicación agrícola, fue incluido en 1859 en la relación de los montes enajenables pertenecientes a los pueblos, pese a su carácter de bien comunal. Sin embargo, la enajenación no llegó a producirse y los terrenos del Puig Llorença continuaron siendo administrados por una Junta Rectora integrada por quince vecinos de Benitachell que eran los sucesores de los elegidos por el duque en el momento de la formación de dicho organismo. La gestión de esta Junta, que se renovaba por herencia, consistía fundamentalmente en el alquiler de los pastos y en el cobro de una serie de tasas en concepto de aprovechamientos forestales que eran posteriormente invertidos en el pago de la contribución del monte, en obras benéficas y en la preparación de los actos festivos del municipio. En consecuencia, podría considerarse que el Puig Llorença es uno de los ejemplos más sobresalientes de la situación que cita Garrido Falla al afirmar que el «fantasma» de la Desamortización hizo que muchos montes municipales pasaran a manos de una comunidad de vecinos, si bien preservando el aprovechamiento común ${ }^{6}$.

En 1965 la denominada Junta de Horno y Monte de Benitachell sucumbió ante una crisis que venía sufriendo a lo largo de varios años como consecuencia de la evolución de los sistemas de producción y de los cambios socio-económicos. El resultado fue la donación del monte al Ayuntamiento mediante transferencia gratuita firmada por los quince copropietarios. Así fue como el Puig Llorença fue incluido en el Inventario General de Bienes Patrimoniales, pasando a convertirse en monte de propios un predio que había pertenecido al común de vecinos.

A finales de los años sesenta, el Ayuntamiento de Benitachell se planteó la venta del monte a una sociedad urbanizadora con el fin de convertir en espacio turístico un terreno de casi nula rentabilidad económica y, con los beneficios obtenidos, dotar al municipio de agua potable, alcantarillado y obras de infraestructura y de equipo comunitario. El proceso de venta se inició en 1970, año en que la compañía alemana «V.A.P.F., S. A.» adquirió el primer sector, con una cabida de 114 hectáreas; y la privatización del monte fue consumada tres años después, al adquirir la misma sociedad el otro sector sacado a subasta, procedente del monte comunal, y algunas parcelas privadas enclavadas en su interior ${ }^{7}$.

La redacción y aprobación del consiguiente Plan Parcial, bajo la denominación «Cumbre del Sol», se produjo en 1975 con la finalidad de crear en el monte varios

\footnotetext{
${ }^{6}$ GARRIDO FALLA. «Sobre los bienes comunales», Revista de la Vida Local, 1926, n. ${ }^{\circ}$ 125, p. 682.

${ }^{7}$ VERA REBOLLO, F. Turismo y urbanización en el litoral alicantino, Op. cit., p. 178.
} 
núcleos turísticos-residenciales. A tal efecto, se realizó la subdivisión del área total en dos sectores de dimensiones diferentes -367,8 y 738,5 hectáreas- y cada uno de ellos se parceló a su vez en seis unidades. Conviene señalar, no obstante, que el polígono para el cual se redactó el Plan Parcial abarca únicamente seis de las unidades establecidas, que son las tres primeras de cada sector, quedando el resto de las unidades pendientes de la redacción de un segundo Plan Parcial en el futuro.

En cuanto a la distribución de usos del suelo, el Plan Parcial de 1975 establece una clasificación del terreno en función de la pendiente, panorámica y orientación, de modo que las zonas de pendiente más acusada quedan libres, las de pendiente comprendida entre el 35 y $60 \%$ se dedican a viviendas unifamiliares agrupadas, a fin de conseguir fácilmente vistas sobre el mar, y las de pendiente inferior al 35\% se destinan a la construcción de viviendas unifamiliares aisladas. Los fondos de vaguadas y otros terrenos sin vistas al mar deben, teóricamente, quedar reservados para zonas verdes de uso colectivo, aunque este principio ha sido en la práctica trasgredido en más de un caso. Resulta asimismo paradójico, a la vista del resultado real, el compromiso indicado en el Plan Parcial de evitar «cualquier discordancia que pueda deteriorar la estética del conjunto», y la intención de emplear un estilo arquitectónico mediterráneo, basado en el típico riu-rau de la comarca. En efecto, las repercusiones paisajísticas y medioambientales derivadas de la urbanización del monte han sido enormemente degradantes y destructoras para una masa forestal ya afectada por procesos seculares de tala, roturaciones arbitrarias y sobreexplotación.

Estos efectos medioambientales de signo negativo no han sido tomados en consideración por el Ayuntamiento de Benitachell debido al gran número de ventajas socio-económicas igualmente derivadas de la urbanización del monte, que han permitido al municipio desarrollar una serie de mejoras de infraestructura y que han fomentado las actividades ligadas a los sectores secundario y terciario. Sin embargo, y ante la evidencia y la gravedad de los hechos, la Comisión Provincial de Urbanismo de Alicante, con motivo de la aprobación de las Normas Subsidiarias del Municipio en 1987, ordenó la redacción de un Plan Especial de Protección para el área delimitada por el Plan Parcial «Cumbre del Sol» y suspendió asimismo la concesión de licencias de obras de edificación hasta que el terreno afectado contase con esta Ordenación. Contra el dictamen de la Comisión Provincial, tanto el Ayuntamiento de Benitachell como la mercantil «V.A.P.F., S. A.» interpusieron recursos de alzada ante la Consellería de Obras Públicas, Urbanismo y Transportes de la Generalidad Valenciana, pero el conflicto de intereses surgido acerca de la urbanización hizo necesario finalmente la suscripción de un convenio urbanístico entre ambas partes, con el fin de compatibilizar el mantenimiento y la protección de los espacios naturales con las expectativas de la empresa promotora y con las perspectivas de riqueza y empleo generadas en el municipio por la construcción del núcleo turístico-residencial.

El Convenio Urbanístico adoptado en enero de 1988 perseguía como objetivo prioritario la protección y defensa de los valores paisajísticos y ecológicos del Puig Llorença, con el fin de garantizar el futuro desarrollo de la construcción y promoción inmobiliaria por los cauces de una mayor idoneidad urbanística en términos cualitativos, fundamental para el mantenimiento del desarrollo socio-económico del municipio de Benitachell. Para ello, la compañía «V.A.P.F., S. A.», se comprometía a sacrificar los enclaves más espectaculares de la urbanización, como son las zonas de los acantilados y la cumbre del monte, para crear un cinturón verde de protección de impacto de $2.854 .000 \mathrm{~m}^{2}$. Ello suponía la permuta de una serie de terrenos entre «V.A.P.F., S. A.» y el Ayuntamiento de Benitachell. En efecto, la sociedad promotora había de permutar $400.710 \mathrm{~m}^{2}$ de suelo 
calificado como zona de vivienda agrupada y unifamiliar, zona de poblado marítimo y zona hotelera, por terrenos de igual extensión, propiedad del Ayuntamiento, calificados como «Suelo No Urbanizable de Protección», que serían reclasificados y pasarían a convertirse en Suelo Urbanizable. En consecuencia, el Convenio exigía la modificación puntual de las Normas Subsidiarias de Planeamiento y del Plan Parcial «Cumbre del Sol», con el fin de que el terreno que pasaba a la propiedad de «V.A.P.F, S. A.» fuera calificado como suelo urbanizable, al tiempo que los que pasaban a la propiedad del Ayuntamiento fueran calificados como suelo no urbanizable de especial protección.

Finalmente, la empresa «EUREN, S. A.» ejecutó en 1989 el Plan Especial de Protección del Puig Llorença y Les Morres de Benitachell, desarrollando el proyecto de reordenación urbanística de la «Cumbre del Sol», de acuerdo con lo establecido en el citado Convenio Urbanístico, y modificando alguno de los puntos fundamentales del Plan Parcial aprobado en 1975.

\section{Proliferación de las actuaciones urbanísticas}

A pesar de que el Plan Parcial «Cumbre del Sol» ha sido el proyecto de mayor envergadura llevado a cabo en el municipio de Benitachell, diversas operaciones urbanísticas desarrolladas de modo paralelo han contribuido igualmente a la configuración del espacio turístico-residencial.

En 1975 el Ayuntamiento promovió la redacción del Plan Parcial «Pueblo Alcasar», que fue aprobado por la Comisión Provincial de Urbanismo al año siguiente y cuyo desarrollo ha dado lugar a la creación de una urbanización con carácter de ciudad-jardín, formada por viviendas unifamiliares de estilo mediterráneo. También en este caso el Plan Parcial ha sido objeto de un proyecto de remodelación que ha modificado la zonificación del suelo inicialmente establecida. Conviene destacar, no obstante, el fuerte contraste existente entre el tipo y la calidad de las construcciones, así como en cuanto al estado de las infraestructuras desarrolladas en el Plan Parcial «Cumbre del Sol» y en el Plan Parcial «Pueblo Alcasar». Este último, con edificaciones de mayor calidad y con una estética arquitectónica bastante más cuidada, denota la presencia de un turismo de calidad media-alta ${ }^{8}$.

Enclavada también en la partida del Alcasar, y lindando al norte con la parcela ordenada por el Plan Parcial «Pueblo Alcasar», ha sido construida la urbanización denominada «El Madroñal», que ocupa una superficie total de $153.824 \mathrm{~m}^{2}$ sobre las estribaciones meridional y occidental del Puig Llorença. La misma entidad promotora que planteó en 1979 la redacción de este Plan Parcial sobre suelo rústico de interés turístico, se encargó en 1987 de la elaboración de otro Plan Parcial bajo la denominación de «Golden Valley». Este nuevo complejo turístico-residencial queda ubicado en la misma partida rural que las dos anteriores, lindando al oeste con «El Madroñal». Conviene señalar que la superficie ordenada por el Plan Parcial «Golden Valley» había sido con anterioridad incluida en el de «Don Pedro», redactado en 1977, que afectaba a terrenos ubicados en los términos municipales de Benitachell y Teulada, y que no llegó a desarrollarse por no haber alcanzado su aprobación definitiva.

El Plan Parcial «Valle del Portet» guarda también una relación de continuidad respecto del Plan Parcial «Don Pedro», y constituye, al igual que el Plan Parcial «Golden

\footnotetext{
${ }^{8}$ VERA REBOLLO, F. Turismo y urbanización en el litoral alicantino, Op. cit., p. 318.
} 


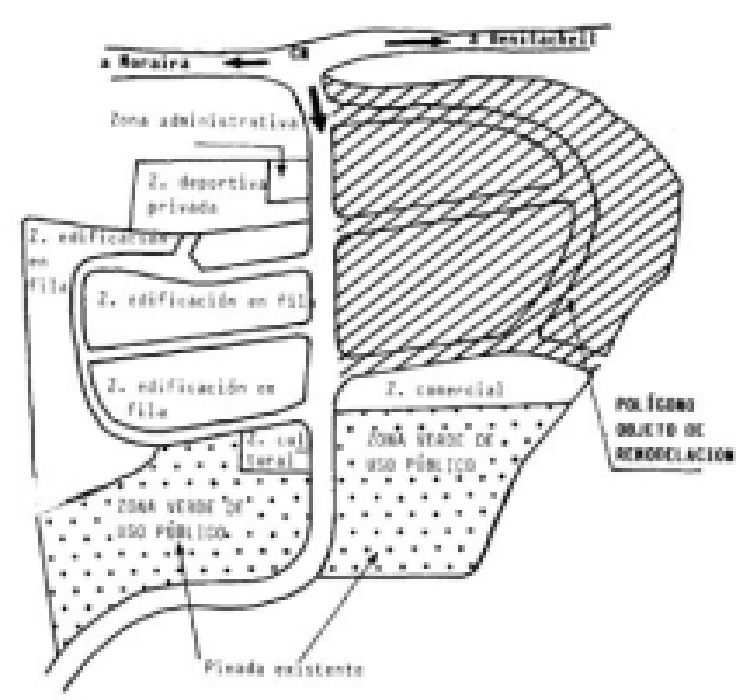

Figura 2. Esquema de zonificación del Plan Parcial «Pueblo Alcasar» de Benitachell.

Valley», una reordenación de parte de los terrenos ya contemplados en el proyecto que no llegó a realizarse, con la correspondiente actualización y puesta al día de sus determinaciones y con ligeras rectificaciones sobre el mismo. La aprobación del Plan Parcial «Valle del Portet» tropezó con ciertas dificultades, al tratarse de una urbanización proyectada en el fondo de un barranco, al igual que la denominada «Golden Valley», y por tanto expuesta a riesgos de inundación. Sin embargo, la Confederación Hidrográfica del Júcar emitió un informe favorable al respecto y el Plan Parcial fue definitivamente aprobado en marzo de 1988.

Los últimos Planes Parciales aprobados en el municipio, y que se encuentran actualmente en su fase inicial, son los denominados «Calistros y Asegaor» y «Les Fonts». En ambos casos, se trata de la actuación de promotoras con domicilio social en Jávea, cuyo objetivo es la creación de núcleos residenciales para satisfacer la creciente demanda de la zona. La tipología de las viviendas a construir, al igual que en el resto de las actuaciones, consiste en la combinación de una zona de edificación agrupada y otra de viviendas unifamiliares aisladas. Estos Planes Parciales no han supuesto una problemática del estilo de la planteada por los proyectos anteriores; únicamente en torno a la aprobación del Plan Parcial «Calistro y Asegaors» surgieron ciertas vicisitudes que fueron superadas rápidamente mediante una política de adquisición de los terrenos objeto de la futura urbanización. 


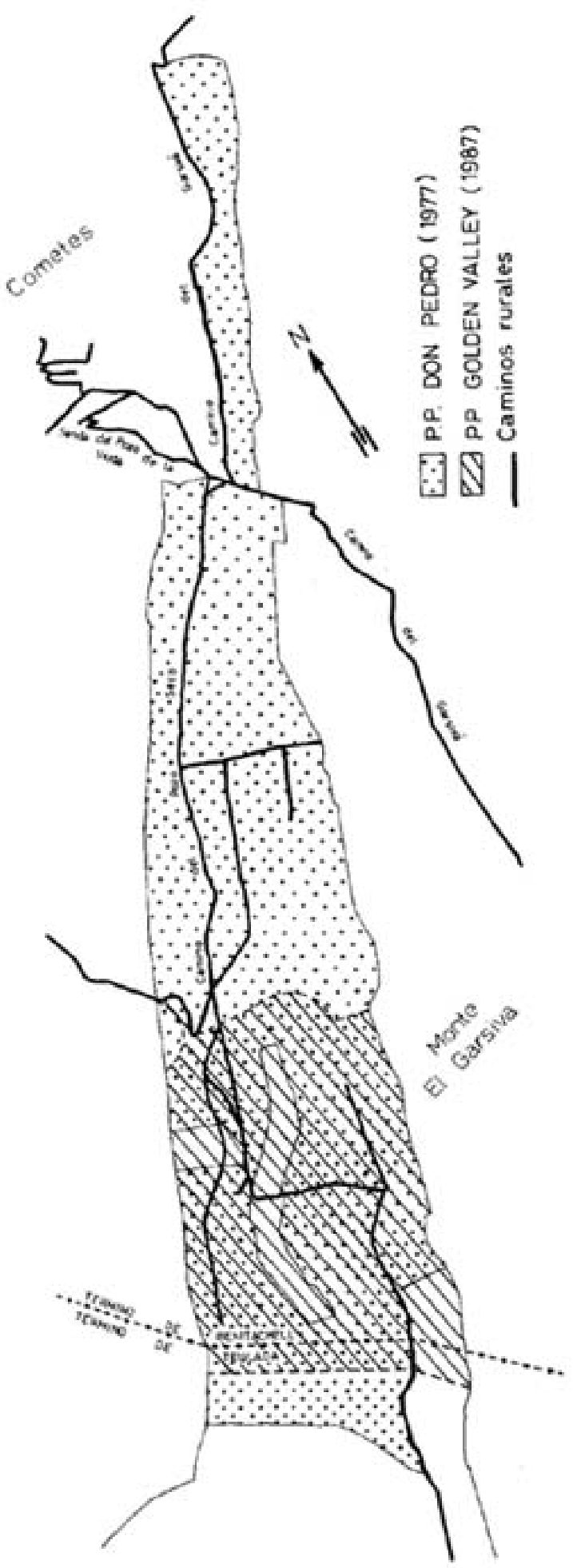

Figura 3. Plano del emplazamiento catastral del Plan Parcial «Golden Valley» de Benitachell, inserto en el proyecto previo del Plan Parcial de Ordenación Turístico-Residencial «Don Pedro», que afectaba a los términos de Benitachell y Teulada. 
ACTUACIONES URBANÍSTICAS DESARROLLADAS

EN EL MUNICIPIO DE BENITACHELL CON FINES TURÍSTICO-RESIDENCIALES

\begin{tabular}{|c|c|c|c|c|}
\hline & Superficie $\left(\mathrm{m}^{2}\right)$ & Viviendas & Habitantes & Viv./hab. \\
\hline Cumbre & 3.676 .108 & 4.975 & 19.900 & 13,5 \\
\hline Alcasar & 115.810 & 231 & 924 & 20,0 \\
\hline Madroñal & 153.824 & 171 & 684 & 11,1 \\
\hline Golden Valley & 95.139 & 100 & 400 & 10,5 \\
\hline Valle Portet & 139.784 & 177 & 708 & 12,7 \\
\hline Castellons Vida & 10.200 & 20 & 70 & 20,0 \\
\hline Les Fonts & 159.801 & 250 & 950 & 15,6 \\
\hline Calistro & 202.485 & 231 & 924 & 11,4 \\
\hline TOTAL & 4.553 .151 & 6.155 & 24.560 & 14,3 \\
\hline
\end{tabular}

La evolución del número de licencias municipales de obras concedidas es uno de los indicadores más significativos y elocuentes para el análisis de la implantación turístico-residencial en una zona. En el caso de Benitachell, la curva evolutiva de las licencias de obras concedidas en relación con el fenómeno turístico a lo largo del período 1977-1988 es fiel reflejo de las vicisitudes atravesadas por el municipio en materia de planeamiento urbanístico. Efectivamente, a partir de 1978 se observa una disminución tanto del número de licencias concedidas como de los ingresos municipales resultantes de su concesión, y esta tendencia, paralela a la fase de preparación de un nuevo Plan General de Ordenación Urbana que se adaptase a la nueva Ley del Suelo, no se invierte hasta 1981, momento en que se inicia el ya comentado «vacío de normativa» en lo relativo al suelo urbanizable. Aprovechando esta coyuntura de ambigüedad se produjo una creciente demanda y concesión de licencias de obras hasta que en 1984 se clarificó la situación y comenzaron a redactarse las Normas Subsidiarias de Planeamiento actualmente vigentes. Las curvas evolutivas relativas a las licencias de obras presentan, en general, tendencias bastante claras y regulares. El único pico sobresaliente en la evolución de los ingresos municipales anuales resultantes de la concesión de licencias de obras es el que se produce en 1986, a causa de la concesión en este año de la licencia correspondiente a la futura construcción de un Hotel-Apartamento de cuatro estrellas en el emplazamiento más próximo al mar de la urbanización «Cumbre del Sol». Este proyecto fue posteriormente modificado, al producirse la ya referida permuta de terrenos entre «V.A.P.F., S. A.» y el Ayuntamiento de Benitachell, pero en la reforma del Plan Parcial inicial se contemplaba la posibilidad de ubicar el hotel en otro lugar, renunciando en todo caso la mercantil a la construcción en la zona de los acantilados y demás terrenos junto al mar.

Conviene por último destacar el importante volumen de ingresos que percibe el Ayuntamiento como resultado de la concesión de licencias de obras y, en particular, la cuantía derivada de concesiones realizadas para la urbanización del Puig Llorença, lo que justifica el apoyo incondicional que ha recibido «V.A.P.F., S. A.» a instancias municipales ante cualquier tipo de conflicto urbanístico. 


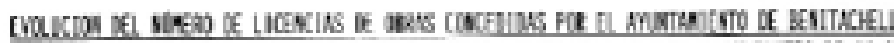

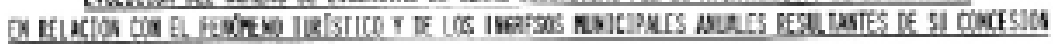

\begin{tabular}{|c|c|c|c|c|c|c|c|c|c|}
\hline & GEES EL DLL & D.ES) ULeses & 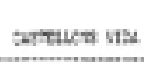 & nunstic & cuss mive & 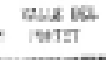 & socs & \multicolumn{2}{|c|}{ 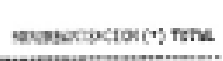 } \\
\hline 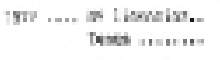 & W:Aย & $\cos : 12$ & & & & & & $20.41^{2}$ & w. \\
\hline 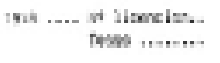 & t.senas & $\cos x$ & & & & & sets.sen & $=19$ & 2.18. 38 \\
\hline 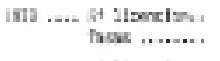 & $2.12 \pi x$ & 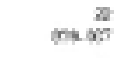 & & & & & & 1625 & 2.02 .83 \\
\hline 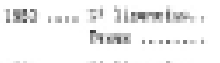 & M.TW & $\cos 2$ & & & & & & $=7$ & $x \in, 2 a$ \\
\hline 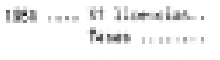 & Auses & SLES & & & & & & $\operatorname{ros}^{2}$ & 6. \\
\hline $\begin{array}{l}\text { tWa .... } 50 \text { liseretise. } \\
\text { labes ......... }\end{array}$ & ผ. 로․ & No. 8 & & & & & & a) & $\operatorname{Lin} x=4$ \\
\hline 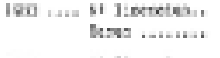 & $\begin{aligned} 4 \\
\cos a s\end{aligned}$ & wast & & & & & & 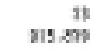 & 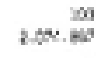 \\
\hline 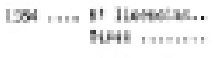 & 1.res.m & $\nabla .81$ & $\operatorname{tansk}$ & $\underset{1.10 .0 \times 1]}{1]}$ & & & & nit. & $\begin{aligned} \mathrm{TS} \\
\text { iest.an }\end{aligned}$ \\
\hline 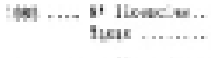 & 2000 & xair & astin & ax.ext & & & & שล..2 & $2 .=18$ \\
\hline 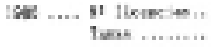 & D. 204.75 & $\sin x$ & & ansen & & & 2.xo & $\begin{aligned} 15 \\
3.515 .4 \% ?\end{aligned}$ & 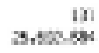 \\
\hline 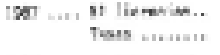 & 2.Tn, 16 & $\begin{array}{rl}x & x \\
-\infty & 100\end{array}$ & & $\sin 1$ & ma.zi & $\begin{array}{l}11 \\
\operatorname{sag} x x\end{array}$ & 2.250 & $1.5 n \cdot 45$ & 5. Whese \\
\hline 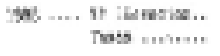 & 364.245 & $\begin{aligned} 12 \\
\text { mosts }\end{aligned}$ & & $\operatorname{ten} 3 x^{3}$ & 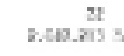 & $\sin \frac{\pi}{\pi}$ & 50.28 & $4,318.046$ & 14.sac. in \\
\hline
\end{tabular}

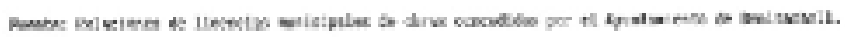

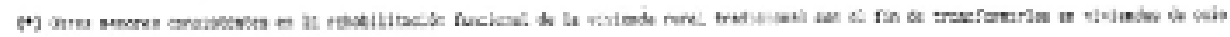




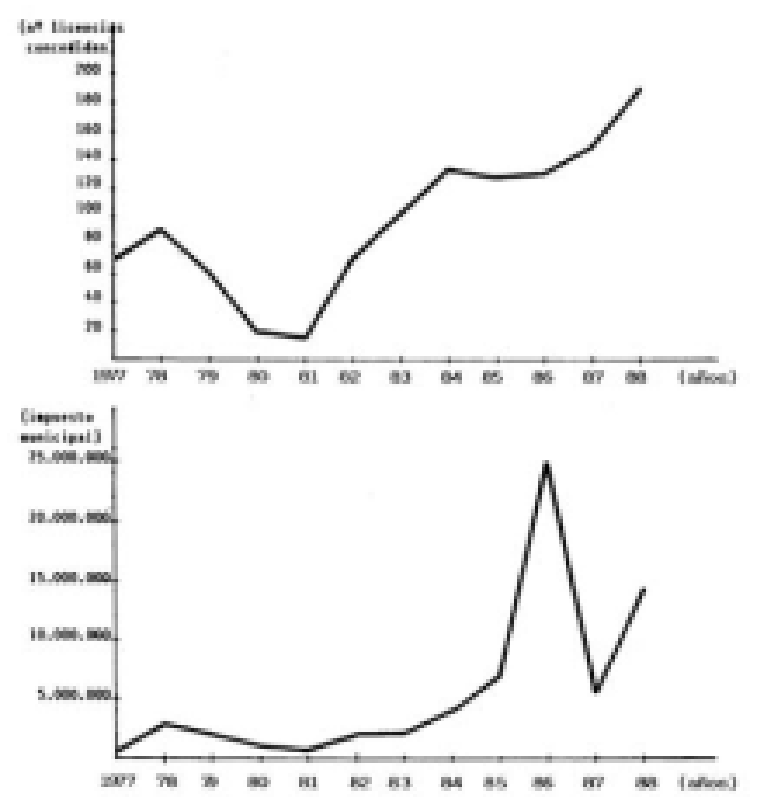

FUENTE: Relaciones de Licencias Municipales de Obras concedidas por el Ayuntamiento de Benitachell durante el período de años 1977-1988.

Gráfico 2. Evolución del número de licencias de obras en relación con el fenómeno turístico y de los ingresos municipales anuales resultantes de su concesión (1977-1988).

\section{Conclusiones}

Como consecuencia de la implantación del fenómeno turístico en Benitachell, se ha producido en el municipio una serie de transformaciones sobre el territorio de muy diversa índole. El auge del turismo se ha manifestado con retraso respecto al resto de los 
municipios costeros de la comarca del Marquesado, pero ha generado en un corto espacio de tiempo un gran número de cambios socio-económicos y ha acelerado la degradación del medio natural.

Es indudable que el turismo ha supuesto para Benitachell una importante fuente de ingresos, y que una de sus repercusiones más positivas ha sido el fomento de la industria de la construcción y de otras ramas industriales inducidas por ella, así como el desarrollo de las actividades incluidas en el sector terciario, que se han superpuesto sobre una tradicional base agraria. Baste señalar, en este sentido, que el número de obras mayores construidas en 1984 se había duplicado con respecto a las iniciadas en 1982 y triplicado respecto a 1983. Estas obras han sido, en su mayoría, realizadas fuera del núcleo urbano, de modo que éste apenas se ha visto afectado por el auge del turismo, gracias a su posición marginal respecto a la línea de costa. Únicamente en cuanto a la creación y mejora de la infraestructura urbana (dotación de agua potable, alcantarillado y aceras, entre otras realizaciones), se ha dejado sentir la influencia del turismo en el núcleo de población, de modo que éste no ha recibido sino ventajas derivadas de la riqueza generada por la construcción de núcleos turístico-residenciales.

Los beneficios económicos inducidos por la implantación turística en el municipio han contribuido igualmente al aumento del nivel de vida de sus habitantes. Al mismo tiempo, la proliferación de las actividades secundarias y terciarias ha supuesto la ampliación y diversificación de la oferta de empleo, favoreciendo de este modo el aumento de los efectivos demográficos, gracias a la detención del éxodo rural y a la llegada de nuevos inmigrantes al municipio.

Sin embargo, la creación de núcleos turístico-residenciales ha ido generalmente en detrimento de la conservación de los valores ecológicos y paisajísticos. De hecho, la actuación urbanística de mayor envergadura se ha desarrollado sobre la unidad de relieve más importante del municipio, y las estribaciones occidentales de la misma han sido además calificadas como suelo urbanizable, y elegidas como emplazamiento de la mayoría de los planes parciales aprobados. En definitiva, la planificación de núcleos turístico-residenciales no ha contemplado en su desarrollo la preservación del medio natural, sino que ha sido realizada a espaldas del mismo y con criterios exclusivamente economicistas. Conviene destacar la trascendencia que adquiere este hecho ante la magnitud alcanzada por el fenómeno turístico en Benitachell, donde a finales de 1989 se preveía la dotación de viviendas residenciales para una población teórica de 24.560 habitantes. Esta cifra contrasta fuertemente con el volumen alcanzado por la población del municipio, que en 1986 era de 1.609 habitantes.

En consecuencia, se hace necesario el control de la actividad urbanística en Benitachell, a través de la redacción de un Plan Especial de Protección del Medio Físico, con el fin de armonizar el desarrollo turístico y económico con la protección de los valores paisajísticos y ecológicos del municipio y definir la capacidad de acogida y el impacto ambiental derivado del crecimiento de los asentamientos turístico-residenciales. Esta política se revela, en cualquier caso, como la única viable y la más idónea para garantizar la cualificación de una oferta turística basada en la existencia de unos recursos medioambientales atractivos. 